\title{
Presynaptic Inhibition of Excitatory Synaptic Transmission Mediated by $\alpha$ Adrenergic Receptors in Area CA3 of the Rat Hippocampus in vitro
}

\author{
Massimo Scanziani, Beat H. Gähwiler, and Scott M. Thompson \\ Brain Research Institute, University of Zurich, $\mathrm{CH}-8029$ Zurich, Switzerland
}

\begin{abstract}
We have investigated the action of norepinephrine (NE) on excitatory synaptic transmission in the hippocampus by recording from CA3 pyramidal cells in organotypic slice cultures. NE (5 $\mu \mathrm{M})$ was found to decrease the amplitude of pharmacologically isolated EPSPs elicited with stimulation of mossy fibers or recurrent axon collaterals (mean decrease in EPSP amplitude, 44\%). Desensitization was observed with repetitive applications. NE did not affect the sensitlvlty of CA3 cells to iontophoretically applied AMPA, and did not affect the amplitude distribution of TTX-resistant, miniature excitatory synaptic currents. These data suggest that NE acts at presynaptic receptors to decrease glutamate release. This action of NE was blocked by the $\alpha$ receptor antagonist phentolamine and the specific $\alpha_{1}$ receptor antagonist prazosine, but not by the $\beta$ receptor antagonist timolol or the $\alpha_{2}$ receptor antagonist idazoxan. Inhibition of EPSPs by NE was prevented by pretreatment of cultures with pertussis toxin, indicating that G-proteins couple these receptors to their effectors. Stimulation of protein kinase $C$ with phorbol ester blocked the action of NE on EPSPs. This effect, as well as the desensitization of NE responses, was reduced by application of the protein kinase inhibitor staurosporin.

Presynaptic inhibition of excitatory synaptic transmission, mediated by $\alpha$ adrenergic receptors, represents a novel modulatory action of NE in the hippocampus.
\end{abstract}

[Key words: presynaptic inhibition, EPSPs, hippocampus, norepinephrine, glutamate, desensitization]

The hippocampus receives a prominent adrenergic innervation from the locus coeruleus (Moore and Bloom, 1979). Both stimulation in the locus coeruleus, to evoke release of endogenous norepinephrine (NE), and topical application of exogenous $\mathrm{NE}$ have been shown to decrease the spontaneous activity of hippocampal pyramidal neurons in vivo (Segal and Bloom, 1974a,b; Mueller et al., 1982; Curet and de Montigny, 1988a,b; cf. Olpe et al., 1986). In contrast, NE exerts a dual action on hippocampal activity in vitro. $\mathrm{NE}$ was shown to both decrease and increase the amplitude of the population spike recorded from the stratum

\footnotetext{
Received Mar. 5, 1993; revised June 11, 1993; accepted June 17, 1993.

We are indebted to F. Grogg, L. Rietschin, and R. Schöb for technical assistance, Drs. P. Vincent and C. Staub for sharing their computer programs, and Drs. M. Capogna and U. Gerber for reading the manuscript. This work was supported by Sandoz Pharma Ltd. (Basle, Switzerland), the Dr. Eric Slack-Gyr Foundation, and the Swiss National Science Foundation (31-27641.89).

Correspondence should be addressed to Scott M. Thompson, Brain Research Institute, University of Zurich, August Forel-Strasse 1, CH-8029 Zurich, Switzerland.

Copyright (C) 1993 Society for Neuroscience $0270-6474 / 93 / 135393-09 \$ 05.00 / 0$
}

pyramidale. These two effects are mediated by $\alpha$ and $\beta$ adrenergic receptors, respectively (Mueller et al., 1981; Mynlieff and Dunwiddie, 1988). Likewise, $\alpha$ adrenergic agonists reduce the frequency of spontaneous epileptiform discharge in vitro, while $\beta$ adrenergic agonists have a proconvulsive action (Mueller and Dunwiddie, 1983).

The NE-induced increase in hippocampal excitability probably results from the well-characterized $\beta$ receptor-mediated reduction of $\mathrm{Ca}^{2+}$-dependent $\mathrm{K}^{+}$conductance (Madison and Nicoll, 1986). On the other hand, neither the cellular basis nor the pharmacology of the $\alpha$ receptor-mediated inhibitory effect of adrenergic agonists in the hippocampus has been unequivocally established. Madison and Nicoll (1986) observed a small $\alpha$ receptor-mediated hyperpolarization, accompanied by a decrease in input resistance, in a portion of the CAl pyramidal cells studied. However, the variability and small size of this effect seem unlikely to underlie the consistently observed inhibition of hippocampal activity in vivo and in vitro.

Indirect evidence suggests that NE may modulate excitatory synaptic transmission in the hippocampus (Mody et al., 1983; Doze et al., 1991). We have therefore investigated the effects of NE on isolated EPSPs in hippocampal slice cultures.

Portions of these data have been presented in abstract form (Scanziani et al., 1992b).

\section{Materials and Methods}

Organotypic hippocampal slice cultures were prepared as described previously (Gähwiler, 1981). Briefly, hippocampal slices ( $400 \mu \mathrm{m}$ thick) were obtained from 6-7-d-old rat pups, embedded in a chicken plasma clot on glass coverslips, and placed in test tubes containing semisynthetic medium. The cultures were then incubated on a roller drum for at least 2 weeks before experimentation, allowing for the disappearance of damaged tissue and a flattening to only one or two cells in thickness, while maintaining the normal hippocampal cytoarchitecture.

Mature cultures were placed in a recording chamber on an inverted microscope and perfused with warmed $\left(34^{\circ} \mathrm{C}\right.$ ) saline containing (in $\mathrm{mM}$ ) $\mathrm{Na}^{+}, 148.9 ; \mathrm{K}^{+}, 2.7 ; \mathrm{Cl}^{-}, 150.2 ; \mathrm{Ca}^{2+}, 3.8 ; \mathrm{Mg}^{2+}, 1.5 ; \mathrm{HCO}_{3}{ }^{-}, 11.6 ;$ $\mathrm{H}_{2} \mathrm{PO}_{4}{ }^{-}, 0.4$; glucose, 5.6 ; and phenol red, $10 \mathrm{mg}$ /liter. Microelectrodes (30-80 M $\Omega$ ) were filled with $2 \mathrm{M} \mathrm{KCl}$ or $0.5 \mathrm{M}$ potassium methylsulfate, and recordings were made in either current-clamp or single-elcctrodc voltage-clamp mode $(1-4 \mathrm{kHz}$ switching frequency). Excitatory postsynaptic potentials were elicited with stimuli $(0.1 \mathrm{msec})$ delivered via $155 \mathrm{~mm} \mathrm{NaCl}-$ filled microelectrodes $(3 \mathrm{M} \Omega$ ) placed either within the dentate gyrus, or in stratum radiatum of area CA1. Stimulation intensity $(-10$ to $-200 \mu \mathrm{A})$ was adjusted to elicit EPSPs of 5-10 $\mathrm{mV}$ in amplitude. AMPA ( $\pm-\alpha$-amino-3-hydroxy-5-methylisoxazole-4-propionic acid; 10 $\mathrm{mm}$ at $\mathrm{pH}$ 8) was iontophoretically applied in some experiments using patch pipettes positioned close to the cell body of the recorded cell. Numerical data in the text and figures are presented as mean \pm STD and mean \pm SEM, respectively.

Spontaneous, miniature excitatory synaptic currents (mEPSCs) were recorded in whole-cell voltage clamp as described previously (Scanziani 
A

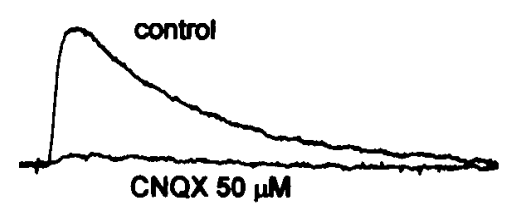

B

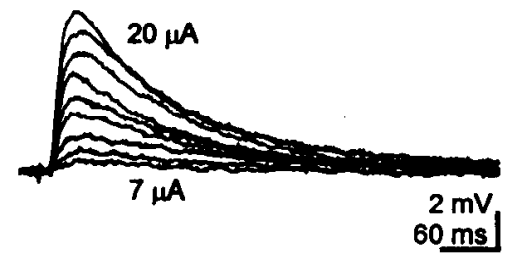

C

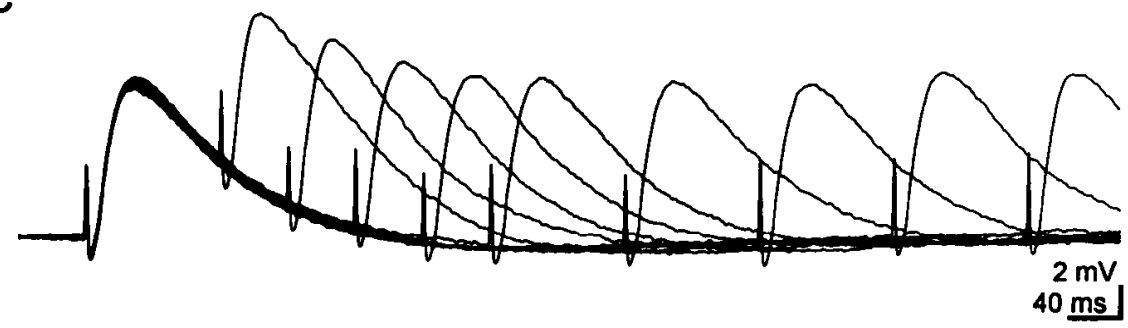

Figure 1. Isolation of monosynaptic AMPA/kainate receptor-mediated EPSPs. Responses were elicited with stimulation in the dentate gyrus in the presence of bicuculline $(40 \mu \mathrm{M})$, CGP $35348(500 \mu \mathrm{M}), \Lambda P 5(20 \mu \mathrm{M})$, and CNQX $(10 \mu \mathrm{M})$. $A$, Increasing the concentration of the competitive antagonist CNQX to $50 \mu \mathrm{M}$ strongly reduced the amplitude of the isolated EPSP, indicating that it was mediated by AMPA/kainate receptors. $B$, Responses of same cell to stimulation of the mossy fibers at increasing intensities. Note that the amplitude increased progressively and without obvious discontinuities. Membrane potential, $-75 \mathrm{mV} ; \mathrm{KCl}$ electrode. $C$, Different cell, same conditions. Nine superimposed sweeps show the response of a CA3 neuron to two paired mossy fiber stimuli, separated from each other by progressively decreasing interstimulus intervals. Note that the EPSPs were able to follow stimulation frequencies up to $10 \mathrm{~Hz}$, without changes in latency or amplitude. Membrane potential, $-75 \mathrm{mV}$; potassium methylsulfate electrode.

et al., 1992a). Pipettes containcd (in mM) CsF, 125; HEPES, 10; and tetracesium BAPTA, 3. Tetrodotoxin (TTX; $0.5 \mu \mathrm{M}$ ) was added to the bathing solution to block action potential-dependent transmitter release, bicuculline $(40 \mu \mathrm{M})$ to block $\mathrm{GABA}_{\mathrm{A}}$ receptors, and $50 \mathrm{mM}$ sucrose to increase the frequency of mEPSCs in order to facilitate comparison of amplitude distributions. We have previously established that this procedure increases $m E P S C$ frequency two- to threefold, without affecting mEPSC amplitude (Scanziani et al., 1992a). For statistical comparisons of mEPSC amplitude distributions, cumulative probability plots were prepared from large numbers of responses $(>100)$ and the likelihood that two distributions were different was assessed using the Kolmogorov-Smirnov test. Two distributions were considered different if $p<0.05$.

Drugs were applied by bath application, except for AMPA, and were obtained from the following sources: 6-cyano-7-nitro-quinoxaline-2,3dione (CNQX), D-2-amino-5-phosphovalerate (AP5), and AMPA, Tocris Neuramin (Bristol, UK); pertussis toxin, List Biological Laboratories (Campbell, CA); TTX, Janssen Chimica (Geel, Belgium); staurosporin, Boehringer (Mannheim, Germany); BAPTA, Molecular Probes (Eugene, OR); and phorbol 12,13-dibutyrate (PDBu) and all adrenergic agonists and antagonists, Sigma (St. Louis, MO).

\section{Results}

In order to study the effect of NE on excitatory transmission independently from the NE-induced changes in inhibitory transmission (Leung and Miller, 1988; Madison and Nicoll, 1988; Doze et al., 1991), we examined the effects of NE on pharmacologically isolated EPSPs (Thompson and Gähwiler, 1992). Inhibitory synaptic transmission was blocked with the $\mathrm{GABA}_{\mathrm{A}}$ receptor antagonist bicuculline $(40 \mu \mathrm{M})$ and the $\mathrm{GABA}_{\mathrm{B}}$ receptor antagonist CGP $35348(500 \mu \mathrm{M})$. High concentrations of the NMDA receptor antagonist AP5 $(20-40 \mu \mathrm{M})$ and a nonsaturating concentration of the non-NMDA receptor antagonist CNQX $(10 \mu \mathrm{M})$ were used to prevent epileptiform burst discharges. Stimulation in the dentate gyrus of hippocampal slice cultures (1/12 sec for the entire duration of the experiment) then evoked small EPSPs in CA3 cells. These EPSPs depended linearly on membrane potential (not shown), could be strongly reduced by incrcasing the concentration of CNQX (Fig. $1 A$ ), and are thus mediated by non-NMDA receptors. At membrane potentials between -60 and $-80 \mathrm{mV}$, the evoked responses had an average amplitude of $7.5 \pm 1.9 \mathrm{mV}(n=56)$. The isolated EPSPs had a constant latency and single peak over a range of stimulation intensities (Fig. 1B), exhibited a monophasic decay, and followed stimulation frequencies up to $10 \mathrm{~Hz}$ without any changes in amplitude or latency (Fig. 1C). These results indicate that pharmacologically isolated EPSPs result from the monosynaptic activation of many synapses, presumably formed by mossy fibers. The contribution of polysynaptic pathways is seemingly negligible, since these pathways should produce a second peak to the EPSP, with longer latency, and be unable to follow high frequencies of stimulation.

Bath application of NE ( $5 \mu \mathrm{M})$ reversibly decreased the amplitude of isolated EPSPs by $44 \pm 13 \%$ (range, $13-82 \%, n=39$ ) (Fig. $2 A$ ). This action of NE was rapid in onset, and reached its maximal effect within 1-2 min. Recovery of EPSP amplitude ( $97 \pm 13 \%$ of control amplitude) was observed 10-20 min after ceasing drug perfusion (Fig. $2 A$ ). NE also caused a decrease of $46 \pm 15 \%(n=6)$ in the amplitude of EPSPs elicited with the stimulating electrode placed in stratum radiatum of area $\mathrm{CA} 1$, in an attempt to activate antidromically the axons of adjacent CA3 pyramidal cells (Fig. 3). Because these EPSPs should be predominantly mediated by local recurrent collaterals (and possibly some monosynaptic $\mathrm{CA} 1-\mathrm{CA} 3$ projections), it is likely that all fast excitatory inputs to the CA3 cells are sensitive to NE. The following experiments were all performed on EPSPs evoked with stimulation within the dentate gyrus, however.

The effect of NE on isolated EPSPs was observed to fade with multiple applications. In experiments in which NE was applied twice, allowing for complete recovery of EPSP amplitude between applications (10-20 $\mathrm{min}$ ), the first application reduced EPSP amplitude by $43 \pm 12 \%$, while a second application produced a significantly smaller reduction of only $23 \pm 13 \%(n=$ $12 ; p<0.005$, paired $t$ test) (see Fig. 7C). 


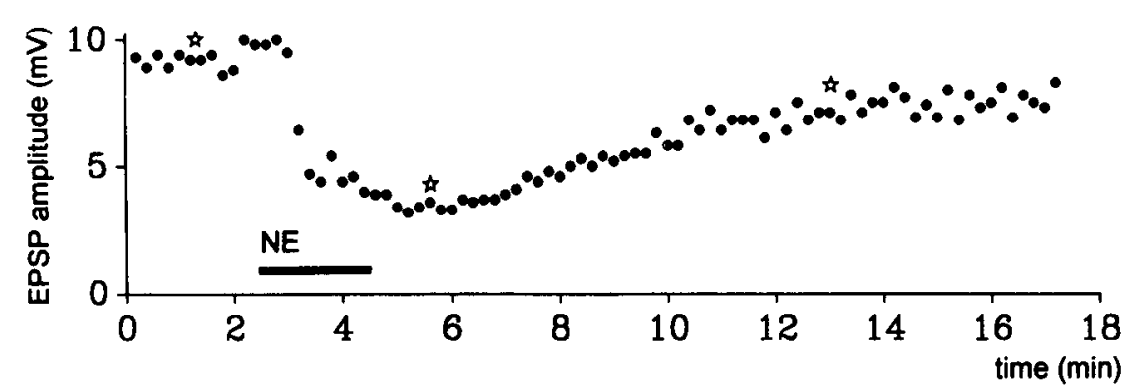

control NE r recovery

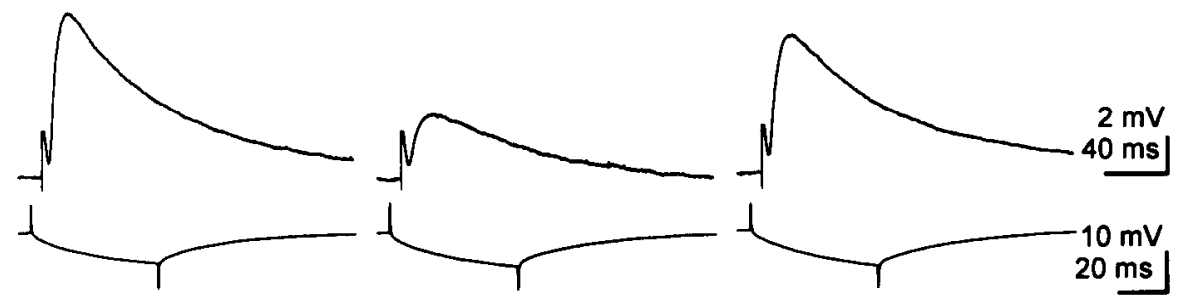

B

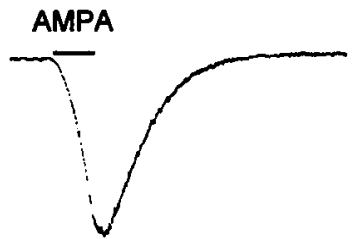

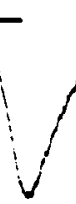
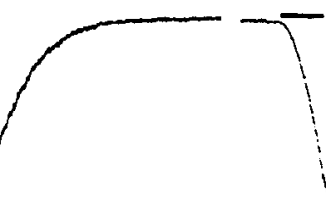

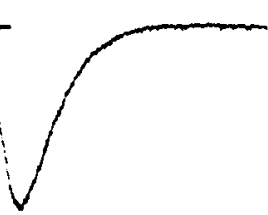

$100 \mathrm{pA}$

$5 \mathrm{~s}$
Figure 2. Effect of $\mathrm{NE}$ on isolated EPSPs and AMPA-induced currents. $A$, NE $(5 \mu \mathrm{M})$ reversibly reduced the amplitude of the pharmacologically isolated EPSP recorded in a CA3 neuron after mossy fiber stimulation. Representative EPSPs from the indicated times (stars) are shown below the graph. In this and subsequent figures, each sweep represents the average of 5-10 episodes. NE had no observable effect on the passive membrane characteristics of the cell assessed by injecting hyperpolarizing current pulses $(-0.125$ $\mathrm{nA}, 50 \mathrm{msec}$ ). Membrane potential, -57 $\mathrm{mV}$; potassium methylsulfate electrode. $B$, Different cell: inward current evoked by a $4 \mathrm{sec}$ iontophoretic pulse of AMPA (horizontal bars) in a singleelectrode voltage-clamped CA3 neuron in the presence of TTX $(0.5 \mu \mathrm{M})$ and bicuculline $(40 \mu \mathrm{M})$. Note that bath application of NE $(5 \mu \mathrm{M})$ had no major effect on the amplitude of the inward current, suggesting that NE exerts its effects on EPSPs via presynaptic inhibition. Holding potential, $-64 \mathrm{mV} ; \mathrm{KCl}$ electrode.

\section{Does norepinephrine act pre- or postsynaptically?}

Decreases in EPSP amplitude may reflect decreases in the presynaptic release of glutamate or in the postsynaptic glutamate sensitivity. The linear dependence of the EPSP amplitude on membrane potential, as well as its reduction by CNQX, indicates that the glutamate receptor subtype mediating the EPSP under our conditions belongs to the AMPA/kainate class. We therefore compared the response of single-electrode voltageclamped $\mathrm{CA} 3$ pyramidal cells to iontophoretically applied AMPA, before and during perfusion of NE (Fig. 2B). For these experiments, the cultures were continuously perfused with I'IX $(0.5 \mu \mathrm{M})$ and bicuculline ( $40 \mu \mathrm{M})$. AMPA was iontophoresed (4 sec) at regular intervals $(90 \mathrm{sec})$, with the tip of the iontophoretic pipettes placed close to the recorded neurons. The amplitude of the evoked inward currents ranged from 360 to $890 \mathrm{pA}$, at holding potentials of -60 to $-70 \mathrm{mV}$, and were associated with a $48 \pm 5 \%$ decrease in the control input resistance $(n=4)$. Bath perfusion of CNQX $(20 \mu \mathrm{M})$ reversibly blocked the response to AMPA. NE ( $5 \mu \mathrm{M})$, however, had no significant effect on the amplitude of the evoked AMPA currents ( $99 \pm 3 \%$ of control, $n=5)$. Perfusion of NE in the presence of TTX $(0.5 \mu \mathrm{M})$ and bicuculline $(40 \mu \mathrm{M})$ was not accompanied by any change in holding current greater than $\pm 30 \mathrm{pA}(n=5)$, or any change in the input resistance of the neuron $(103 \pm 6 \%$ of control; $n=$ 4).

These results indicate that the sensitivity of pyramidal cell AMPA receptors is not affected by NE, suggesting that NE decreases EPSP amplitude by reducing the amount of excitatory transmitter release from presynaptic terminals. Nevertheless, the possibility cannot be excluded that iontophoretically applied AMPA activates many extrasynaptic receptors, which may not be under the control of the same regulatory pathways as synaptic receptors. The sensitivity of synaptic glutamate receptors can be assessed through the analysis of miniature synaptic currents. If NE were acting postsynaptically to decrease the sensitivity of pyramidal cells to glutamate, it should also reduce the amplitude of miniature excitatory synaptic currents.

Whole-cell recording from CA3 neurons, in the presence of TTX $(0.5 \mu \mathrm{M})$ and bicuculline $(40 \mu \mathrm{M})$, allowed the detection of

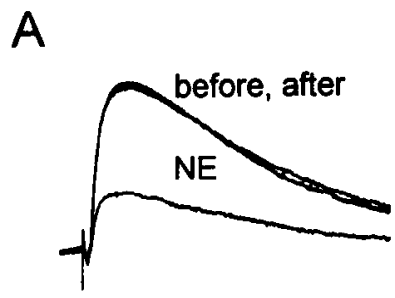

dentate stim.
B

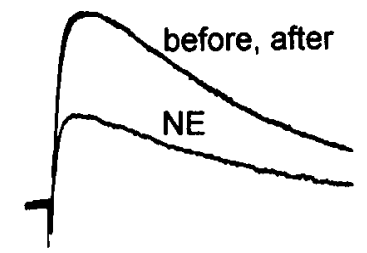

$2 \mathrm{mV}$
Figure 3. NE decreases the amplitude of recurrent collateral- and mossy fiber-evoked pharmacologically isolated EPSPs: response of a CA3 neuron to the stimulation of two different synaptic inputs. The stimulating electrodes were placed within the dentate gyrus for mossy fiber stimulation $(A)$ and in the stratum radiatum of area CAl to antidromically activate recurrent collaterals $(B)$. Note that NE $(5 \mu \mathrm{M})$ reduced the amplitude of both synaptic inputs to a similar extent. Membrane potential, $-57 \mathrm{mV}$; potassium methylsulfate electrode. 


\section{evoked EPSCs}

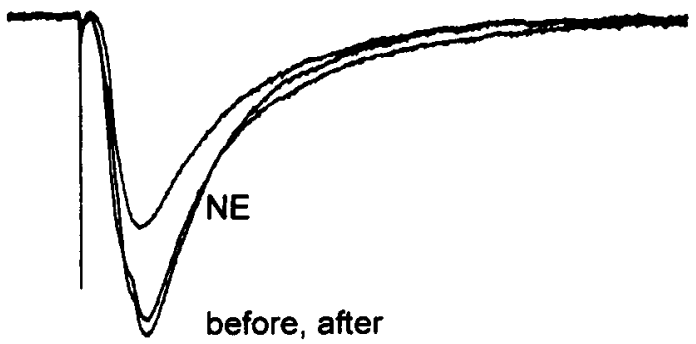

\section{mEPSCs}

\section{control}

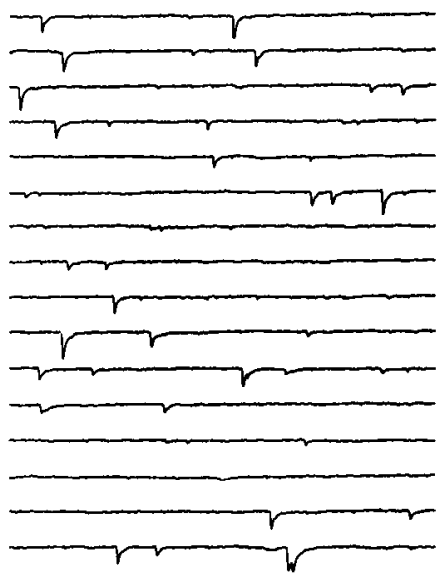

Figure 4. NE does not affect the frequency or amplitude distribution of mEPSCs. Upper panel, NE $(5 \mu \mathrm{M})$ inhibited excitatory synaptic currents evoked with mossy fiber stimulation, as recorded from a whole-cell voltageclamped CA3 neuron using a CsF-based intracellular solution to block GABA and $\mathrm{GABA}_{\mathrm{B}}$ receptor-mediated $\mathrm{Cl}^{-}$and $\mathrm{K}^{+}$conductances. Holding potential, $-64 \mathrm{mV}$. Middle panels, Different cell: spontaneous, TTX-resistant mEPSCs recorded from a whole-cell voltageclamped CA3 neuron in the presence of bicuculline $(40 \mu \mathrm{M})$. Bath application of NE did not affect the frequency or amplitude of mEPSCs. Holding potential, $-100 \mathrm{mV}$. Lower panel: Left, Same cell: amplitude distribution of the mEPSCs before and after NE application (not significantly different, $p>0.99$, Kolmogorov-Smirnov test; number of events analyzed, 184 and 164). Right, Pooled data from five cells showing that NE had no effect on the mean amplitude or frequency of mEPSCs. These data are thus consistent with a presynaptic site of NE action.

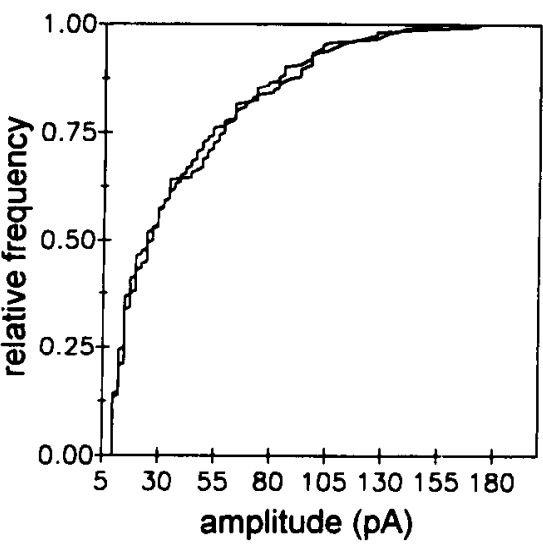

NE
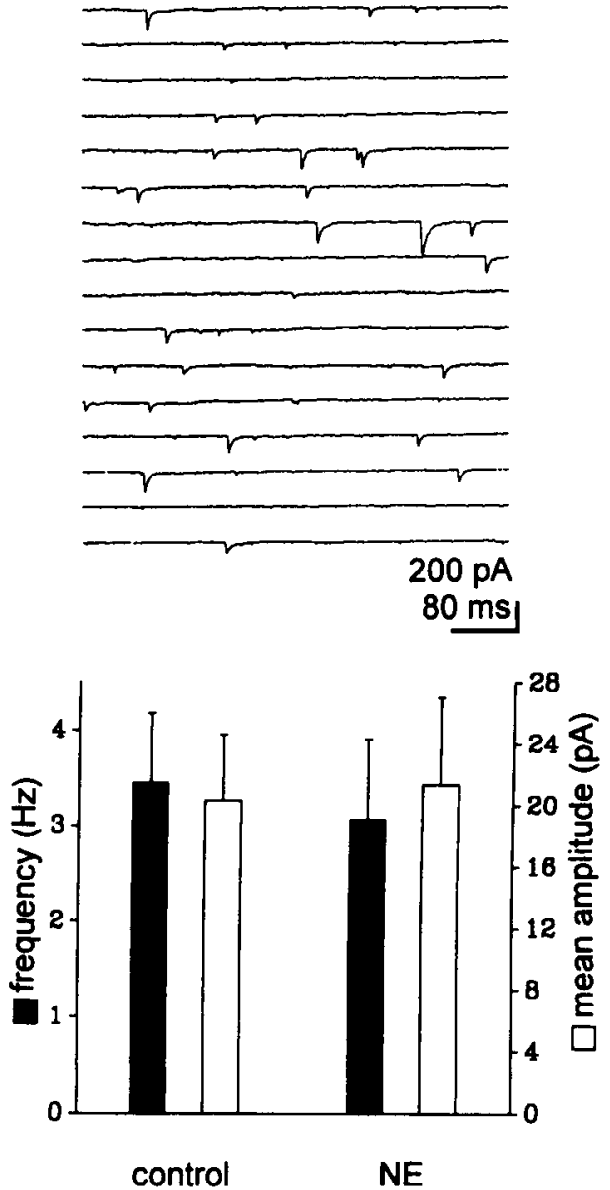

spontaneous inward currents that were abolished by CNQX. The amplitude of these mEPSCs could be as large as $200 \mathrm{pA}$.

NE $(5 \mu \mathrm{M})$ had no significant effect on either the frequency ( $90 \pm 24 \%$ of control) or the distribution of EPSC amplitudes, as determined with the Kolmogorov-Smirnov test $(n=5)$ (Fig. 4). The lack of effect of NE cannot be ascribed to the whole-cell recording conditions, since $5 \mu \mathrm{M}$ NE produced a $51 \pm 12 \%$ decrease in the amplitude of EPSCs in CA3 neurons recorded with whole-cell clamp after mossy fiber stimulation $(n=4$, recovery from $\mathrm{NE}=101 \pm 21 \%$ of control amplitude) (Fig. 4).
This inhibition is thus very similar to the depression of EPSP amplitudes observed in intracellular microelectrode recordings. The failure to observe a change in the amplitude distribution of mEPSC following application of NE further supports the hypothesis of a presynaptic site of NE action.

\section{Pharmacology of the presynaptic norepinephrine receptor}

We used selective adrenergic agonists and antagonists to characterize the pharmacological properties of the receptors mediating the presynaptic inhibition of EPSPs by NE. Because of the 
A

control phentolamine

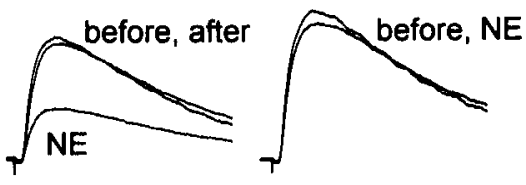

$2 \mathrm{mV}$
$40 \mathrm{~ms}$

B idazoxan prazosin recovery

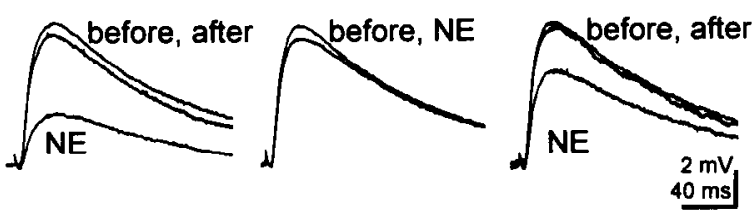

C

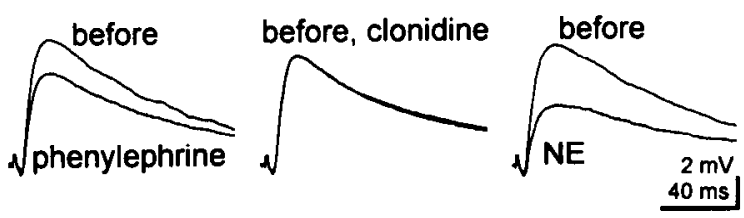

D

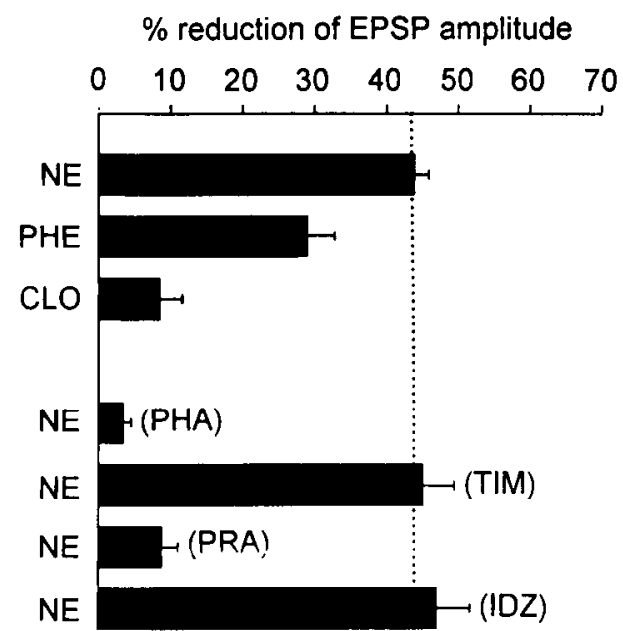

Figure 5. Pharmacological profilc of the adrencrgic receptor mediating the inhibition of pharmacologically isolated EPSPs: responses of CA3 cells to stimulation within the dentate gyrus. $A$, The $\alpha$ receptor antagonist phentolamine $(50 \mu \mathrm{M})$ blocked the depression of the isolated EPSP produced by $5 \mu \mathrm{M}$ NE. Membrane potential, $-84 \mathrm{mV} ; \mathrm{KCl}$ electrode. $B$, Different cell. NE causes a large decrease in EPSP amplitude in the presence of the specific $\alpha_{2}$ receptor antagonist idazoxan $(1 \mu \mathrm{M})$, whereas the effects of NE were virtually eliminated by application of the specific $\alpha_{1}$ receptor antagonist prazosin (500 $\mathrm{nM}$ ). Membrane potential, -70 $\mathrm{mV} ; \mathrm{KCl}$ electrode. $C$, Different cell. The $\alpha_{1}$ receptor-specific agonist phenylephrine $(50 \mu \mathrm{M})$ reduced EPSP amplitude, whereas the specific $\alpha_{2}$ receptor agonist clonidine $(5 \mu \mathrm{M})$ did not affect the amplitude of the EPSP. The effect of phenylephrine on EPSP amplitude was less than that of NE $(5 \mu \mathrm{M})$ in this same cell. Membrane potential, $-65 \mathrm{mV}$; potassium methylsulfatc clcctrode. $D$, Summary of the pharmacology of noradrenergic inhibition of EPSPs. Each column shows the percentage reduction (mean + SEM) of the control EPSP amplitude for a given experimental condition. $N E, 5 \mu \mathrm{M}, n=39 ; P H E$ (phenylephrine), 25$100 \mu \mathrm{M}, n=11 ; C L O$ (clonidine), $5 \mu \mathrm{M}, n=7 ; P H A$ (phentolamine) 50 $\mu_{\mathrm{M}}, n=5$; $T I M$ (timolol) $5 \mu \mathrm{M}, n=8$; PRA (prazosin), $500 \mathrm{nM}, n=6$; $I D Z$ (idazoxan), $500 \mathrm{nM}$ to $1 \mu \mathrm{M}, n=9$.

\section{pertussis toxin treated}

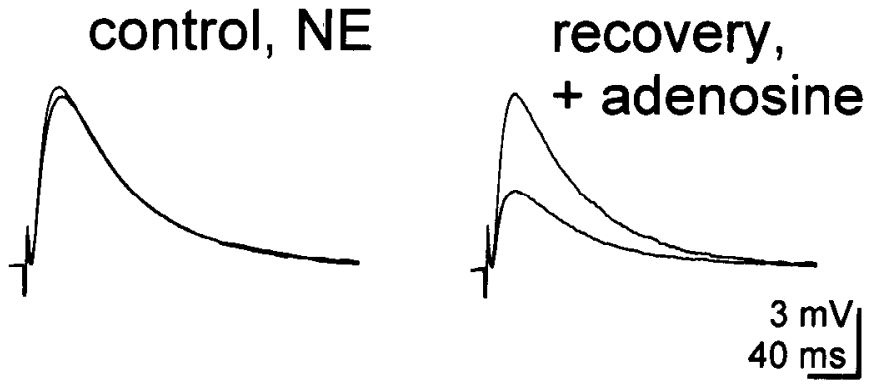

Figure 6. Pertussis toxin treatment specifically affects the presynaptic action of NE. Pretreatment of hippocampal slice cultures with pertussis toxin $(500 \mathrm{ng} / \mathrm{ml}, 48 \mathrm{hr})$ virtually eliminated the ability of NE $(5 \mu \mathrm{M})$ to reduce the amplitude of pharmacologically isolated EPSPs evoked with stimulation within the dentate gyrus. Adenosine, in contrast, was still able to depress the EPSP. Membrane potential, $-60 \mathrm{mV}$; potassium methylsulfate electrode.

fading of successive NE responses, only the first application of agonist is included in the numerical values presented below. In the presence of the $\beta$ receptor antagonist timolol $(5 \mu \mathrm{M})$, NE ( 5 $\mu \mathrm{M})$ decreased the amplitude of isolated EPSPs by $45 \pm 12 \%(n$ $=8$; not shown), that is, to a similar extent as in control saline. On the other hand, bath perfusion of the broad spectrum $\alpha$ receptor antagonist phentolamine $(50 \mu \mathrm{M})$ virtually prevented the NE-mediated depression of the isolated EPSP $(6 \pm 2 \%$ reduction in amplitude, $n=5$ ) (Fig. $5 A$ ). The action of NE was unaffected by the presence of the selective $\alpha_{2}$ receptor antagonist idazoxan $(1 \mu \mathrm{M})(47 \pm 13 \%$ reduction in EPSP amplitude, $n=$ 9), whereas NE depressed the isolated EPSP by only $9 \pm 5 \%$ in the presence of the $\alpha_{1}$ receptor antagonist prazosin $(0.5-1 \mu \mathrm{M})$ $(n=6)$ (Fig. 5B). These data are summarized in Figure 5D.

Taken together, these results implicate presynaptic $\alpha_{1}$ receptors in the action of NE on EPSPs. The specific $\alpha_{1}$ agonist phenylephrine, however, was not equally effective as NE, even if applied at concentrations that take into account the 15-fold higher affinity of $\alpha_{1}$ receptors for NE in the hippocampus (Lomasney et al., 1991). Phenylephrine (50-100 $\mu \mathrm{M}$ ) reversibly reduced the isolated EPSP amplitude by only $29 \pm 11 \%(n=11$, recovery $=94 \pm 10 \%$ of control amplitude) (Fig. $5 C$ ), significantly (Wilcoxon test, $p<0.01$ ) less than the action of $5 \mu \mathrm{M}$ of $\mathrm{NE}$ (see above). On the other hand, the specific $\alpha_{2}$ agonist clonidine (1-5 $\mu \mathrm{M})$ had virtually no effect on EPSP amplitude ( 9 $\pm 8 \%$ reduction, $n=7$; significantly less than the effect of phenylephrine, $p<0.01$, Wilcoxon test) (Fig. $5 C$ ). We have not attempted to characterize further the subtype of $\alpha$ receptor involved in this response.

\section{$G$-proteins, protein kinase $C$, and presynaptic $\alpha$ adrenergic receptors}

One subtype of $\alpha_{1}$ adrenergic receptor that has recently been cloned $\left(\alpha_{1 \mathrm{~A}}\right)$ is abundantly expressed in the rat hippocampus and has a putative transmembrane topology similar to that of known G-protein-coupled receptors (Lomasney et al., 1991). Pertussis toxin inactivates several distinct types of G-proteins, and has been shown to prevent the action of several agonists modulating transmitter release. For these reasons, we examined the effect of pertussis toxin on NE-mediated inhibition of iso- 
A

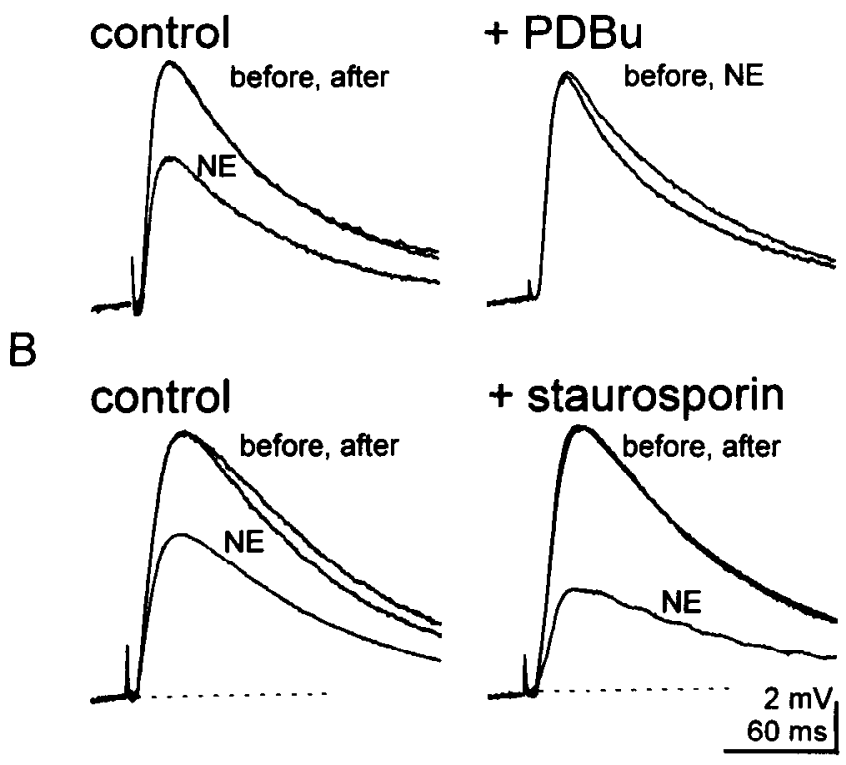

C

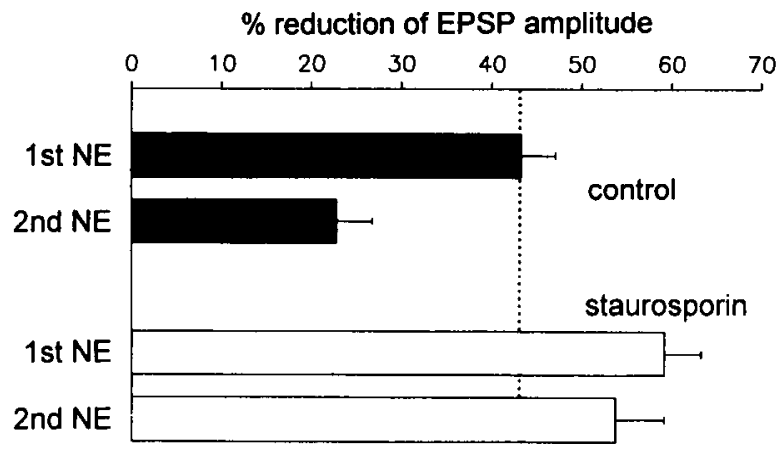

Figure 7. Influence of PKC on adrenergic presynaptic inhibition and desensitization. A, After perfusion of the PKC activator PDBu (200 nM, $10 \mathrm{~min})$, NE $(5 \mu \mathrm{M})$ was no longer able to reduce the amplitude of the pharmacologically isolated EPSP evoked with stimulation in the dentate gyrus. Because PDBu caused an increase of the amplitude of the EPSP, the stimulation intensity was reduced so that the EPSP returned to its original amplitude. Membrane potential, $-65 \mathrm{mV}$; potassium methylsulfate electrode. $B$, Different cell, same conditions. The depression of the isolated EPSP by NE $(5 \mu \mathrm{M})$ was potentiated by $68 \%$ after application of the protein kinase inhibitor staurosporin $(1 \mu \mathrm{M})$. Membrane potential, $-74 \mathrm{mV}$; potassium methylsulfate electrode. $C$, Pooled data from untreated cells (solid bars; $n=12$ ) and cells treated with 1-2 $\mu \mathrm{M}$ staurosporin (open bars; $n=5$ ). With two applications of NE, the inhibition of EPSPs was significantly less for the second application than the first. In the presence of staurosporin, however, the second response to NE was not significantly different than the first. Note also that staurosporin potentiated the presynaptic inhibition of EPSPs by NE.

lated EPSPs. After pretreatment of hippocampal slice cultures with pertussis toxin $(500 \mathrm{ng} / \mathrm{ml}$ for $48 \mathrm{hr})$, the inhibitory action of NE was found to be virtually abolished $(7 \pm 10 \%$ reduction, $n=10$ ) (Fig. 6). Pretreatment with pertussis toxin did not unspecifically impair all presynaptic modulation mechanisms, however, since $50 \mu \mathrm{M}$ adenosine still induced a depression of the isolated EPSP (Fig. 6), in agreement with previous findings (Fredholm et al., 1989; Thompson et al., 1992).

Stimulation of protein kinase C (PKC) has been shown to inactivate skeletal muscle $\alpha_{1}$ receptors (Leeb-Lundberg et al., 1985). Perfusion of hippocampal cultures with the PKC activator PDBu (100-500 nM) invariably led to an increase in the amplitude of isolated EPSPs of $39 \pm 11 \%(n=4$; not shown). We therefore reduced the stimulation intensity in order to return the amplitude of the isolated EPSP to the control level, thus allowing a quantitative comparison of NE action. Perfusion of PDBu completely eliminated the action of NE $(5 \mu \mathrm{M})$ on isolated EPSPs $(4 \pm 10 \%$ reduction, $n=6$ ) (Fig. $7 A$ ).

After incubation of cultures for 1-2 hr with 1-2 $\mu \mathrm{M}$ of the protein kinase antagonist staurosporin, PDBu (100-500 nM) failed to block the noradrenergic depression of isolated EPSPs, indicating a specific action of the phorbol ester. In the presence of staurosporin, the decrease in EPSP amplitude elicited by NE after application of PDBu was $38 \pm 10 \%(n=5$, not shown).

The effect of NE on the isolated EPSP was significantly ( $p<$ 0.01 , Wilcoxon test) enhanced after application of staurosporin $(1-2 \mu \mathrm{M})(60 \pm 8 \%$ reduction in EPSP amplitude, $n=11)$ (Fig. $7 B$ ). This observation suggests that constitutively active protein kinases tonically modulate the efficacy of presynaptic $\alpha$ receptors.

Staurosporin was also found to abolish the desensitization observed with multiple NE applications. Whercas the effect of NE was $50 \%$ less in the second of two applications in control cultures, as described above, in staurosporin-treated cultures the inhibition of EPSP amplitude was $59 \pm 8 \%$ for the first application and $54 \pm 10 \%$ for a second application given $<20$ min later $(n=5$ cells; not significantly different, $p>0.4$, paired $t$ test) (Fig. 7C).

\section{Discussion}

In the present study, we report that NE inhibits pharmacologically isolated EPSPs recorded in CA3 pyramidal cells of hippocampal slice cultures. These EPSPs were evoked in the presence of the NMDA receptor antagonist AP5, after blockade of the early and late component of the IPSP by bicuculline and CGP 35 348, respectively. A nonsaturating concentration of the non-NMDA receptor antagonist CNQX was applied in order to prevent epileptiform burst discharges. Under such conditions, the isolated EPSP had the characteristics of a monosynaptic, AMPA/kainate receptor-mediated response. EPSPs evoked with stimulation of either mossy fibers or recurrent axon collaterals of CA3 pyramidal cells were both decreased in amplitude by bath application of NE. The depression of isolated EPSPs by NE was accompanied by neither a reduction in postsynaptic sensitivity to iontophoretically applied AMPA nor a change in the amplitude distribution of mEPSCs, indicating a presynaptic site of action. We conclude that NE acts via presynaptic receptors to decrease the evoked release of transmitter from excitatory terminals of both mossy fibers and CA 3 pyramidal cell recurrent collaterals.

There are conflicting reports about the action of NE on EPSPs in hippocampal slices (cf. Mody et al., 1983; Hopkins and Johnston, 1988), perhaps reflecting both desensitization of presynaptic adrenergic receptors (see below), as a result of tonic NE release from fibers damaged during the slicing procedure, and adrenergic disinhibition, which results in an indirect enhancement of EPSPs (Madison and Nicoll, 1988). Indeed, the effect of NE reported here is likely to represent the mechanism underlying the decreased excitation of interneurons responsible for this disinhibition (Doze et al., 1991).

The inhibition of EPSPs by NE was unaffected by timolol, 
blocked by phentolamine and prazosin but not idazoxan, and mimicked by phenylephrine but not by clonidine. This pharmacological profile is consistent with the involvement of an $\alpha_{1}$ adrenergic receptor. It is important to note, however, that the $\alpha_{1}$ agonist phenylephrine was considerably less potent than NE, even with applied at a concentration that should compensate for the difference in affinity of the two agonists reported for recombinant hippocampal $\alpha_{1}$ receptors (Lomasney et al., 1991). A similar difference in activity between NE and phenylephrine was observed in previous physiological and biochemical studies on cortical slices (Brown et al., 1984; Minneman and Johnson, 1984; Dodt et al., 1991), suggesting that phenylephrine is a partial agonist at these receptors.

Noradrenergic modulation of transmitter release has been observed in many different systems, including terminals of locus coeruleus neurons, sympathetic neurons (for review, see Starke, 1987), and mitral and granule cells of the olfactory bulb (Trombley and Shepherd, 1991). Our evidence for a presynaptic $\alpha_{1}$ receptor-mediated action of NE is somewhat unexpected, however, since adrenergic presynaptic receptors are typically classified as $\alpha_{2}$ (Starke, 1987). Activation of $\alpha_{1}$ receptors in noncortical regions of the CNS usually decreases postsynaptic $\mathrm{K}^{+}$ conductances, thus increasing neuronal excitability (e.g., North and Yoshimura, 1984; Aghajanian, 1985; McCormick and Prince, 1988). Our results are consistent, however, with the observation that the inhibition of population spike amplitude by NE in the CAl region of the hippocampal slice is mediated by the activation of a prazosin-sensitive $\alpha$ adrenergic receptor (Mynlieff and Dunwiddie, 1988). Furthermore, the inhibitory effects of endogenous and exogenous NE in the hippocampus in vivo are also reduced by $\alpha_{1}$ receptor antagonists (Pang and Rosc, 1987; Curet and de Montigny, 1988b). Likewise, inhibition of EPSPs by NE in neocortical slices may be ascribed to $\alpha_{1}$ receptors (Dodt et al., 1991). Considerable evidence of presynaptic inhibition mediated by $\alpha_{1}$ receptors has been obtained in the PNS (e.g., Docherty, 1984; Story et al., 1985; Wetzel et al., 1985). Although we have not yet further characterized the subtype of $\alpha_{1}$ receptor that mediates adrenergic presynaptic inhibition in our experiments, analysis of Northern blots and in situ hybridization data indicates that $\alpha_{1 \mathrm{~A}}$ receptors are the predominant subtype expressed in the hippocampus (Lomasney et al., 1991; McCune et al., 1992).

\section{Second messengers and presynaptic $\alpha$ receptors}

Incubation of hippocampal cultures with pertussis toxin was found to prevent the inhibition of EPSPs by NE, indicating an involvement of a G-protcin in the coupling of presynaptic $\alpha$ receptors to their effector mechanism. In addition, application of the PKC activator PDBu eliminated the effect of NE on EPSPs, whereas pretreatment of cultures with the protein kinase antagonist staurosporin enhanced the noradrenergic inhibition of EPSPs. This later finding further suggests that constitutively active PKC may tonically downregulate the effectiveness of NE receptors.

We have observed that multiple applications of NE lead to a pronounced decrease in its ability to inhibit excitatory synaptic transmission. Desensitization of $\alpha_{1}$ receptor-mediated phosphatidylinositol turnover in smooth muscle has been well characterized. Exogenously applied PKC activators strongly attenuate $\alpha_{1}$ receptor-mediated phosphatidylinositol turnover by causing phosphorylation of the $\alpha_{1}$ receptor itself (Leeb-Lundberg et al., 1985). Interestingly, activation of $\alpha_{1}$ receptors also induces a PKC-mediated phosphorylation of the receptor, leading to "homologous" desensitization (Leeb-Lundberg et al., 1987). The deduced amino acid sequence of the $\alpha_{1}$ adrenergic receptor subtype expressed in the hippocampus contains potential sites for phosphorylation by PKC (Lomasney et al., 1991). If in the hippocampus, as well as in smooth muscle, activation of the $\alpha_{1}$ adrenergic receptor promotes PKC activation, which seems likely since $\alpha$ receptor activation increases phosphatidylinositol turnover in the hippocampus (Janowsky et al., 1984), then the model of "homologous" desensitization may explain the reduced effect of NE with multiple applications. Indeed, we have observed that staurosporin application eliminates the desensitization observed with multiple NE applications, indicating that activation of NE receptors stimulates protein kinase and thus exerts a negative feedback on subsequent $\alpha$ receptor-mediated action. It should be noted that this observation does not directly demonstrate phosphorylation of receptors, as PKC may also have other targets "downstream" of the $\alpha_{1}$ adrenergic receptor.

Although $\alpha_{1}$ adrenergic receptors in the hippocampus and neocortex are linked to phosphoinositide hydrolysis (Brown et al., 1984; Janowsky et al., 1984; Minneman and Johnson, 1984; Schoepp et al., 1984), there is no evidence linking phosphatidylinositol turnover with inhibition of synaptic transmission, to our knowledge. In fact, phosphatidylinositol turnover leads to the generation of diacylglycerol, the physiological activator of PKC, which would be expected to increase excitatory transmission (e.g., Malenka et al., 1987). Furthermore, Dutar and Nicoll (1988) found no correlation between the effectiveness of various muscarinic agonists in stimulating phosphatidylinositol turnover and their ability to inhibit excitatory synaptic transmission in the hippocampus.

NE was found to have no effect on the frequency of spontaneous mEPSCs recorded from whole-cell voltage-clamped CA3 pyramidal neurons in the presence of TTX. In contrast, it has recently been shown that activation of presynaptic $\mathrm{GABA}_{\mathrm{B}}$ and adenosine $A_{1}$ receptors located on excitatory terminals, but not block of voltage-gated $\mathrm{Ca}^{2+}$ channels, can reduce the frequency of mEPSCs in the hippocampus (Scanziani et al., 1992a; Scholz and Miller, 1992), suggesting that transmitters can have a direct action on the probability that synaptic vesicles will spontaneously fuse with the presynaptic membrane. We can therefore exclude a direct action of $\mathrm{NE}$ on the transmitter release process. We suggest, rather, that activation of $\alpha$ receptors may modulate presynaptic ionic conductances.

The biphasic effect of NE on the network activity of the hippocampus may result from pharmacologically distinct $\alpha$ receptor-mediated inhibition and $\beta$ receptor-mediated excitation (Mueller et al., 1981). Activation of $\beta$ receptors has been shown to induce a long-lasting enhancement of the population spike in the CA1 region (e.g., Heginbotham and Dunwiddie, 1991) and to play a facilitatory role in the induction of long-term potentiation of mossy fiber synapses (Hopkins and Johnston, 1988). Increases in intrinsic pyramidal cell excitability following $\beta$ receptor activation (Madison and Nicoll, 1986; Gray and Johnston, 1987; Dunwiddie et al., 1992) probably underlie the increased excitability of the network. The depression in the amplitude of the EPSP upon activation of presynaptic $\alpha$ adrenergic receptors described in this article represents a plausible mechanism responsible for the noradrenergic inhibition of hippocampal activity as described in vivo (Segal and Bloom, 1974a,b; Mueller et al., 1982; Neuman, 1986; Pang and Rose, 1987; Curet 
and de Montigny, 1988a,b) and in vitro (Mody et al., 1983; Mueller and Dunwiddie, 1983; Mynlieff and Dunwiddie, 1988).

The description of opposing actions of NE on $\alpha$ and $\beta$ receptors has some interesting functional implications for neuronal integration: $\alpha$ receptor-mediated presynaptic inhibition will reduce the likelihood that an EPSP will reach the threshold for action potential generation in the postsynaptic cell. Those EPSPs that do reach threshold, however, may produce a larger response, due to the $\beta$ receptor-mediated increase in postsynaptic excitability. These concerted actions support the hypothesis that $\mathrm{NE}$ increases the signal-to-noise ratio in the hippocampus (e.g., Woodward et al., 1979).

\section{References}

Aghajanian GK (1985) Modulation of a transient outward current in serotonergic neurones by $\alpha_{1}$-adrenoreceptors. Nature 315:501-503.

Brown E, Kendall DA, Nahorski SR (1984) Inositol phospholipid hydrolysis in rat cerebral cortical slices: I. Receptor characterisation. J Neurochem 42:1379-1387.

Curet O, de Montigny C (1988a) Electrophysiological characterization of adrenoceptors in the rat dorsal hippocampus. I. Receptors mediating the effect of microiontophoretically applied norepinephrine. Brain Res 475:35-46.

Curet O, de Montigny C (1988b) Electrophysiological characterization of adrenoceptors in the rat dorsal hippocampus. II. Receptors mediating the effect of synaptically released norepinephrine. Brain Res 475:47-57.

Docherty JR (1984) An investigation of presynaptic $\alpha$-adrenoceptor subtypes in the pithed rat heart and in the rat isolated vas deferens. Br J Pharmacol 82:15-23.

Dodt H-U, Pawelzik H, Zieglgänsberger W (1991) Actions of noradrenaline on neocortical neurons in vitro. Brain Res 545:307-311.

Doze VA, Cohen GA, Madison DV (1991) Synaptic localization of adrenergic disinhibition in the rat hippocampus. Neuron 6:889-900.

Dunwiddie TV, Taylor M, Heginbotham LR, Proctor WR (1992) Longterm increases in excitability in the CAl region of rat hippocampus induced by $\beta$-adrenergic stimulation: possible mediation by cAMP. J Neurosci 12:506-517.

Dutar P, Nicoll RA (1988) Classification of muscarinic responses in hippocampus in terms of receptor subtypes and second-messenger systems: electrophysiological studies in vitro. J Neurosci 8:4214-4224.

Fredholm BB, Proctor W, Van der Ploeg I, Dunwiddie TV (1989) In vivo pertussis toxin attenuates some, but not all, adenosine $A_{1}$ effects in slices of the rat hippocampus. Eur J Pharmacol 172:249-262.

Gähwiler BH (1981) Organotypic monolayer cultures of nervous tissue. J Neurosci Methods 4:329-342.

Gray R, Johnston D (1987) Noradrenaline and $\beta$-adrenoceptor agonists increase activity of voltage-dependent calcium channels in hippocampal neurons. Nature 327:620-622.

Heginbotham LR, Dunwiddie TH (1991) Long-term increases in the evoked population spike in the CA1 region of rat hippocampus induced by $\beta$-adrenergic receptor activation. J Neurosci 11:2519-2527.

Hopkins WF, Johnston D (1988) Noradrenergic enhancement of longterm potentiation at mossy fiber synapses in the hippocampus. J Neurophysiol 59:667-687.

Janowsky A, Labarca R, Paul SM (1984) Noradrenergic denervation increases $\alpha_{1}$-adrenoreceptor-mediated inositol-phosphate accumulation in the hippocampus. Eur J Pharmacol 102:193-194.

Leeb-Lundberg LMF, Cotecchia S, Lomasney JW, DeBernardis JF, Lefkowitz RJ, Caron MG (1985) Phorbol esters promote $\alpha_{1}$-adrenergic receptor phosphorylation and receptor uncoupling from inositol phospholipid metabolism. Proc Natl Acad Sci USA 82:5651-5655.

Leeb-Lundberg LMF, Cotecchia S, DeBlasi A, Caron MG, Lefkowitz RJ (1987) Regulation of adrenergic receptor function by phosphorylation. J Biol Chem 262:3098-3105.

Leung PP-H, Miller JJ (1988) Dual role of norepinephrine in the hippocampal CAl region of the rat: inhibition and disinhibition. Can J Physiol Pharmacol 66:814-819.

Lomasney JW, Cotecchia S, Lorenz W, Leung W-Y, Schwinn DA, YangFeng TL, Brownstein M, Lefkowitz RJ, Caron MG (1991) Molecular cloning and expression of the cDNA for the $\alpha_{1 \mathrm{~A}}$-adrenergic receptor. J Biol Chem 266:6365-6369.
Madison DV, Nicoll RA (1986) Actions of noradrenaline recorded intracellularly in rat hippocampal CAI pyramidal neurones, in vitro. J Physiol (Lond) 372:221-244.

Madison DV, Nicoll RA (1988) Norepinephrine decreases synaptic inhibition in the rat hippocampus. Brain Res 442:131-138.

Malenka RC, Ayoub GS, Nicoll RA (1987) Phorbol esters enhance transmitter release in rat hippocampal slices. Brain Res 403:198-203.

McCormick DA, Prince DA (1988) Noradrenergic modulation of firing pattern in guinea pig and cat thalamic neurons, in vitro. $\mathrm{J}$ Neurophysiol 59:978-996.

McCune SK, Voight MM, Hill JM (1992) Devclopmental expression of the alpha-1A, alpha-1B and alpha- $1 \mathrm{C}$ adrenergic receptor subtype mRNAs in the rat brain. Soc Neurosci Abstr 18:457.

Minneman KP, Johnson RD (1984) Characterization of alpha-1 adrenergic receptors linked to $\left[{ }^{3} \mathrm{H}\right]$ inositol metabolism in rat cerebral cortex. J Pharmacol Exp Ther 230:317-323.

Mody I, Leung P, Miller JJ (1983) Role of norepinephrine in seizurelike activity of hippocampal pyramidal cells maintained in vitro: alteration by 6-hydroxydopamine lesions of norepinephrine-containing system. Can J Physiol Pharmacol 61:841-846.

Moore RY, Bloom FE (1979) Central catecholamine neuron systems: anatomy and physiology of the norepinephrine and epinephrine systems. Annu Rev Neurosci 2:113-168.

Mueller AL, Dunwiddie TV (1983) Anticonvulsant and proconvulsant actions of alpha- and beta-noradrencrgic agonists on epilcptiform activity in rat hippocampus in vitro. Epilepsia 24:57-64.

Mueller AL, Hoffer BJ, Dunwiddie TV (1981) Noradrenergic responses in rat hippocampus: evidence for mediation by $\alpha$ and $\beta$ receptors in the in vitro slice. Brain Res 214:113-126.

Mueller AL, Palmer MR, Hoffer BJ, Dunwiddie TV (1982) Hippocampal noradrenergic responses in vivo and in vitro. Naunyn Schmiedebergs Arch Pharmacol 318:259-266.

Mynlieff M, Dunwiddie TV (1988) Noradrenergic depression of synaptic responses in hippocampus of rat: evidence for mediation of alpha -receptors. Neuropharmacology 27:391-398.

Neuman RS (1986) Suppression of penicillin-induced focal epileptiform activity by locus ceruleus stimulation: mediation by an $\alpha_{1}$-adrenoceptor. Epilepsia 27:359-366.

North RA, Yoshimura M (1984) The actions of noradrenalinc on neurones of the rat substantia gelatinosa in vitro. $\mathrm{J}$ Physiol (Lond) 349:43-55.

Olpe H-R, Laszlo J, Pozza MF, DeHerdt P, Waldmeier PC, Jones RSG (1986) Glutamate-induced activation of rat locus coeruleus increases CAl pyramidal cell excitability. Neurosci Lett 65:11-16.

Pang K, Rose GM (1987) Differential effects of norepinephrine on hippocampal complex-spike and $\Theta$-neurons. Brain Res 425:146-158.

Scanziani M, Capogna M, Gähwiler BH, Thompson SM (1992a) Presynaptic inhibition of miniature excitatory currents by baclofen and adenosine in the hippocampus. Neuron 9:919-927.

Scanziani M, Gähwiler BH, Thompson SM (1992b) Presynaptic inhibition of EPSPs by norepinephrine in the area CA3 of hippocampal slice cultures. Soc Neurosci Abstr 18:791

Schoepp DD, Knepper SM, Rutledge CO (1984) Norepinephrine stimulation of phosphoinositide hydrolysis in rat cerebral cortex is associated with the alpha, -adrenoceptor. J Neurochem 43:1758-1761.

Scholz KP, Miller RJ (1992) Inhibition of quantal transmitter release in the absence of calcium influx by a $G$ protein-linked adenosine receptor at hippocampal synapses. Neuron 8:1139-1150.

Segal M, Bloom FE (1974a) The action of norepinephrine in the rat hippocampus. I. Iontophoretic studies. Brain Res 72:79-97.

Segal M, Bloom FE (1974b) The action of norepinephrine in the rat hippocampus. II. Activation of the input pathway. Brain Res 72:99114.

Starke K (1987) Presynaptic alpha-autoreceptors. Rev Physiol Biochem Pharmacol 107:73-146.

Story DF, Standford-Starr CA, Rand MJ (1985) Evidence for involvement of $\alpha_{1}$-adrenoceptors in negative feedback regulation of noradrenergic transmitter release in rat atria. Clin Sci 68[Suppl 10]:111s$115 \mathrm{~s}$.

Thompson SM, Gähwiler BH (1992) Comparison of the actions of baclofen at pre- and postsynaptic receptors in the rat hippocampus in vitro. J Physiol (Lond) 451:329-345.

Thompson SM, Haas HL, Gähwiler BH (1992) Comparison of the actions of adenosine at pre- and postsynaptic receptors in the rat hippocampus in vitro. J Physiol (Lond) 451:347-363. 
Trombley PQ, Shepherd GM (1991) Noradrenergic inhibition of synaptic transmission between mitral and granule cells in mammalian olfactory bulb cultures. J Neurosci 12:3985-3991.

Wetzel GT, Goldstein D, Heller Brown J (1985) Acetylcholine release from rat atria can be regulated through an $\alpha_{1}$-adrenergic receptor. Circ Res 56:763-766.
Woodward DJ, Moises HC, Waterhouse BD, Hoffer BJ, Freedman R (1979) Modulatory actions of norepinephrine in the central nervous system. Fed Proc 38:2109-2116. 